\title{
Empire and the megamachine: comparing two controversies over social media content
}

\section{Stephanie Hill}

Joint Graduate Program in Communication and Culture, Ryerson University \& York University, Toronto, Canada

Published on 31 Mar 2019 | DOI: 10.14763/2019.1.1393

\begin{abstract}
This paper presents the results of a thematic analysis of hearings held before the US senate in 2017 with representatives of social media companies and close coverage from industry groups of advertising boycotts of social media. In response to the public pressure, social media companies increased their investment in machine learning and human moderation to remove inappropriate content and increased transparency initiatives. The two scenarios indicate the importance of content to questions of platform governance and the ability of the advertising industry to act as a platform regulator. This paper uses the political economic analysis of Harold Innis and theoretical work on the megamachine as a framework for understanding how governance may be enacted through commercial systems before and around government policy tools. It argues that social media companies' actions indicate an expanded role for marketing and advertising as governors of media content delivery, resulting in the efficient administration of advertiser concerns while democratic representatives take a comparatively slow road.
\end{abstract}

Keywords: Social media, Governance, Advertising, Megamachine

\section{Article information}

Received: 19 Oct 2018 Reviewed: 18 Jan 2019 Published: 31 Mar 2019

Licence: Creative Commons Attribution 3.0 Germany

Competing interests: The author has declared that no competing interests exist that have influenced the text.

URL:

http://policyreview.info/articles/analysis/empire-and-megamachine-comparing-two-controversies-over -social-media-content

Citation: Hill, S. (2019). Empire and the megamachine: comparing two controversies over social media content. Internet Policy Review, 8(1). DOI: 10.14763/2019.1.1393

This paper is part of Practicing rights and values in internet policy around the world, a special issue of Internet Policy Review guest-edited by Aphra Kerr, Francesca Musiani, and Julia Pohle. 


\section{INTRODUCTION}

This paper considers two major controversies in 2017 over content on social media. The first was within the advertising industry as major brands found that programmatic advertising was appearing next to distasteful, violent, or otherwise objectionable content, particularly on YouTube. As a result, several prominent companies, including Procter \& Gamble, stopped advertising on social media platforms for months or longer. This event, dubbed the "adpocalypse", has had wide ranging effects, particularly on the monetisation of educational and LGBTQ content on YouTube. The second string of events were the first public hearings with representatives of social media companies over Russian operatives disseminating misinformation before, during, and after the 2016 US presidential elections. Misinformation campaigns on social media have since been the subject of government inquiries around the world. The public examinations of these controversies, by senate committees and advertising trade groups, provide insight into major themes of the governance relationships between social media companies and their major stakeholders.

The media, private and public, is essential to political engagement and the construction of democratic culture (Dahlgren, 2009). Arguments for the protection of the public's interest in media typically refer to how government policy should intervene to protect the democratic public interest from the tendencies of private economic interests (Croteau \& Hoynes, 2006). The term public interest lacks precision, however, and what is considered in the public's interest may shift depending on the framework from which it is viewed-a political public interest versus an economic one, for instance (Shtern, 2009). To make matters more complicated, in practice, media governance is divided among a range of actors, including public (government) policy intervention and private (business) media interests. Researchers considering the public interest in communication and media must understand how governance of media is enacted in different contexts and how stakeholders intervene in media systems. Specifically, this paper argues that advertising interests can act as de facto governors of media content delivery in certain contexts, making editorial-style directives as to what content will succeed or fail. This power introduces an understudied layer of governance outside of national policy-making, which follows an inefficient route compared to advertising concerns. This paper uses an historical framework based on Harold Innis' research into the publishing industry in the $18^{\text {th }}$ and $19^{\text {th }}$ centuries, combined with Mumford's (1966) concept of the megamachine, particularly as explored by Latour (1999), to analyse how social media companies are being held accountable to nations and advertisers. Innis' analysis of the print publishing industry demonstrates how freedom of the press laws enabled economic concerns, driven by the advertising industry, to expand the geographic reach of the press and facilitate US cultural imperialism (Innis, 2008). This paper suggests that social media companies are similarly shaped by their reliance on the advertising business model. World governments have largely taken a light approach to regulating social media content while advertisers represent most of those companies' earnings. This paper compares a specific instance of advertisers shaping the rules by which social media companies are governed to public scrutiny by the US government. Both events involve outside actors pressuring social media companies to change their behaviours, with varying degrees of directness and success.

The rise of social media companies, their transnational nature, and the transnational, riskaverse nature of their advertising stakeholders has created an emphasis on brand safety in media content governance. This argument is complementary to work that defines design 
practices as regulation (Yeung, 2017) and arguments that platform content moderation is based in US free speech law, balanced against corporate social responsibility and user expectation (Klonick, 2017). It builds on research that shows that social media platforms attract efforts to regulate content, including social pressure, to prevent certain speakers or practices on the platforms, even those protected by legal rulings (Mueller, 2015). Social media companies are responding to increased public scrutiny by altering how creators and content are moderated and monetised, with impacts on how we understand the platforms' role in enabling expression and circulating information. The public instances of platforms negotiating their accountability to different groups examined in this paper are instructive in understanding how different actors attempt to govern media systems and how media systems respond. Carey (1967) observed that Mumford's ideas of transformation in social organisation are incorporated into Innis' understanding of changes in the technology of communication. This paper combines Innis' work on the press industry with theories of the megamachine, using the two as a novel way to examine the administrative links that govern media systems.

\section{HAROLD INNIS AND THE NEWSPAPER INDUSTRY}

Harold Innis was deeply concerned with the relationship between printing, monopolies of knowledge, and public life. Empire and Communication particularly places the newspaper industry at the centre of US cultural imperialism: "The United States, with systems of mechanized communication and organized force, has sponsored a new type of imperialism imposed on common law in which sovereignty is preserved de jure and used to expand imperialism de facto" (Innis, 2007 [1950], p. 195). Those "systems of mechanized communication," including business models favouring maximum circulation, directly influenced the functioning of later technologies, including the telegraph and the radio. At the time of its creation, the newspaper industry reversed the influence between political centres and peripheries, as the US, then a colony, began providing England with content divorced from English culture and communities (Berland, 1997). Innis argues that while national laws were in effect, they were removed from the details of content and production, so that commercial interests-particularly those of advertisers-could and did govern most daily operations. The US government stepped in only to support industry growth through subsidising mail delivery or facilitating trade relationships. Innis' work on the newspaper industry has significant implications for how we understand social media companies-which have extended the advertising model to new scales and transnational contexts while exerting considerable influence over how information is accessed and circulated by citizens.

The economic framework created by social media companies facilitates content flowing back into the US with unexpected consequences for that country's own democratic processes and cultural stability. If the newspaper affected neighbouring cultures and economies by putting US industries and culture at the heart of global communications, social media may have created opportunities for other actors to move cultural and political content around the globe. National security concerns over political misinformation spreading through social media platforms have increased public scrutiny of social media content regulation and stoked enthusiasm for stricter national restrictions on online content, but these developments are slow when compared to changes made to meet commercial imperatives. Innis argued that commercial imperatives in print media tended to favour circulation over cultural or territorial integrity and that space vacated by policy direction could be filled by directives from commerce. 


\section{BECOMING A VENDIBLE COMMODITY: STRATEGIES OF CIRCULATION}

In the Bias of Communication, Innis locates the beginning of the newspaper's economic model at the lapse of the Licensing of the Press Act. After the Act lapsed, "news became a vendible commodity" (Innis, 2008 [1951], p. 143). The Act was one of many legislative efforts to regulate the press and print industries in the United Kingdom, in this case by requiring that publications be registered (Nipps, 2014). In response to legislative pressures, media structured itself strategically to avoid regulation, shifting formats and obscuring content coverage as political developments made certain formats less expedient. When taxes affected newspapers, there was a rise in other, non-newspaper formats of publication, including publications that circulated on irregular schedules or used unusual page sizes. Innis (2008) depicts these encounters as the negotiation of parliamentary accountability to the people, but it might equally be read as actors in the publishing industry defending their market position and investment in the print industry in the face of uncertain political patronage and funding. Eventually, the need for a predictable source of funds "compelled dependence of the political press on advertisements" (Innis, 2008, p. 153). The print industry turned to the advertising business model in part to escape the uncertainty and risk of political patronage and the inconsistency of tax law and became subject to advertisers' need to grow their audience in the process.

The rise of advertising as a preferred business model for publishing has been covered in detail elsewhere (see $\mathrm{Wu}, 2016)$. What concerns this paper is the technical and political ramifications of that preference. Once newspapers became dependent on advertising dollars, news was important insofar as it attracted readers. Roy Howard, an American publisher speaking before World War I, claimed: "We come here simply as news merchants. We are here to sell advertising and sell it at a rate profitable to those who buy it. But first we must produce a newspaper with news appeal that will result in a circulation and make that advertising effective." (Originally published in Lords of the Press by George Seldes, 1939 in Innis, 2008, p. 181). Advertising requires circulation, and circulation has historically been achieved in publishing through efficient distribution, combined with attention-getting content strategies such as sensationalism, use of images, and exclusive content. The preferences of advertisers hoping to reach national or international audiences pushed technical developments that allowed for the printing of illustrations and the printing and shipping of more papers (Buxton, 1998; Innis, 2007). Paper and printing, instantiated in newspapers whose agendas were set by the demands of advertising, facilitated the connection of wide geographic areas to news, reporting, and advertisements created in a central location. It was the ability of media in this case to assert control over space that led Innis to identify the industry as an agent of US cultural imperialismat the time, an expression of how "any given medium will...favour the growth of certain kinds of interests and institutions at the expense of others" (Carey, 1967, p. 9).

Once the press divorced itself from political money with the aid of advertising, publishers could become less interested in the specifics of content and pursue broader circulation, protecting themselves with freedom of expression laws as necessary. Innis argued that publishing's freedom from direct control over content and its partnership with advertising interests made circulation its priority and allowed information to be treated as a commodity, maximising its spread over geographic space, with implications for affiliated industries and expressions of cultural sovereignty. As technology has moved beyond the printing press, the separation between publishers and content has become pronounced. That is the case of social media 
companies, who have engineered considerable distance in many jurisdictions from laws that ordinarily hold publishers accountable for the speech present on their platforms-a level of licentiousness undreamed of by the news merchants of Innis' analysis. Innis' work remains germane for its insight into advertising as a driving force in technical capability and the entanglement of commercial media with broader economic and political functioning, even as the geographic arrangements that concerned him (such as the focus on US culture as the central director of media development globally) have shifted considerably. Innis' granular examinations of how media outlets were held accountable to laws and the mandates of an advertising business model can act as a model for analysing media interests and institutions.

\section{MEGAMACHINES AND MACHINES FOR GROWTH}

In Innis' account, guarantees of freedom of expression, once in place, rendered the relationship between content and regulation predictable. Once advertisers, regulators, and publishers achieved relative equilibrium in their goals, the industry was able to grow in a manner heedless to geographic location, creating the scale necessary for financial efficiency. One way to understand that operation is as a machine. In Pandora's Hope, Bruno Latour (1999) describes the megamachine as "a large, stratified, externalized body politic" (p. 208). The megamachine organises "large numbers of humans via chains of command, deliberate planning and accounting procedures" (p. 207) to achieve a goal defined by central institutions. The concept of a megamachine was originally theorised by Mumford (1966) as the systems, including but not limited to bureaucracies, that could put large numbers of humans to work on a single goal-organising the military, for instance, or the labour necessary for large-scale construction projects. Mumford argues that the megamachine is essential to technological developments and consisted of "a reliable organisation of knowledge...and an elaborate structure for giving and carrying out orders" (p. 8). Latour's megamachine functions through "nested subprograms” (p. 207) for action that can be tracked across social relationships. Latour suggests that identifying the workings of the subprogrammes may do more to explain collective behaviours and functionalities than discourses about identity (Latour, 1999). The megamachine, then, must be separate from individual or societal wants or preferences. The imperative to "make newspapers", for instance, calls forth systems of salespeople, authors, accountants, publishers, postal workers, and trade relationships that push for increased circulation, regardless of individual preferences within the human systems.

The metaphor of a machine is relatively common in examinations of commodification. For instance, Harvey Molotch's much-cited article The City as a Growth Machine (1976) examines the processes that divorce geographic and other forms of specificity from decision-making in urban development. Those managing transnational communication systems are similarly pursuing freedom from context. A media operation, divorced as much as possible from individual human concerns-achieved through centralisation, technological efficiency and predictable relationships between content and regulation-can be run as a machine. Viewed through the lens of a machine, Innis' analysis of newspapers is a collective of human and industrial processes that became a political body of their own. Innis identifies an industry that he associates with a society (the press in the United States), he then identifies subprogrammes (trade relationships, subsidies, technologies) that encourage the industry to act on wider geographic areas, including neighbouring societies-a media megamachine with the US at its centre. In this scenario, news monopolies, separate from "place, ethics, and community" (Berland, 1997, p. 61), in conjunction with "contemporary transnational capitalism” (p. 68), 
allowed US agendas to dominate global communication.

In a context where the largest media companies are transnational as a rule, Innis' publishing megamachine takes on new aspects. For one, consumer markets across the globe are gaining in importance and institutions for managing global commercial concerns have grown. In her application of Innis' ideas to global media systems, Berland (1997) declared that corporations undermine nation states by undoing their central positioning-putting the corporation at the centre of the media machine, rather than the US state. It may be too soon to declare that corporations have ended US dominance of global communications, but transnational digital communication giants are increasingly tied to diverse social and policy environments. Understanding Innis' "vendible commodity" as a map of the subprogrammes that make up a media megamachine gives researchers a template for examining that machine in a context that has shifted away from one national jurisdiction to a complex, global policy environment. Considering Innis alongside the megamachine, rather than conducting a straightforward political economic analysis, emphasises administrative links over power relations and the construction of a body politic, rather than a market model of competing interests-an idea of particular salience to the advertising industry, which has a particular definition of appropriate content.

\section{THE SOCIAL MEDIA MEGAMACHINE}

Social media companies have emphatically defined themselves as outside of the press and publishing industries because of their reliance on user-generated content, but that distinction is blurring, as statistics place social media high on lists of news sources used by citizens, and professional media content is more prominent on the platforms (Bakshy, Messing, \& Adamic, 2015; Smith, 2017; Burgess, 2015). In the US, Section 230 of the Communication Decency Act, which prohibits providers of online publishing services from being treated as the legal publisher or speaker of information on that service, gives US regulation little power over online platforms (Ardia, 2009; Klonick, 2017). Section 230 has contributed to the impression that social media platforms-as hosts for user-generated content rather than media platforms-are nearly immune to direct regulatory intervention. However, social media companies are governed-directly by national governments as well as through a range of voluntary selfregulation initiatives (in regard to terrorist content, for instance) (Gorwa, 2019). In Europe, and particularly in Germany, direct regulation has recently been used to force social media companies to comply with regional laws and norms. Current efforts are coalescing around competition law, privacy and data protection, and the rollback of intermediary protection from liability (Gorwa, 2019). Other jurisdictions have taken stricter measures, employing tactics such as geo-blocking towards social media companies to prevent them from operating either temporarily or permanently. China has made significant use of this ability and commanded noteworthy concessions from tech companies, such as Google, that wish to access the millions of potential users in that country (Gallagher, 2018). However, nations, no matter how populous, are only one group of stakeholders with fragmented interests. Advertisers represent upwards of 85\% of social media companies' earnings (Facebook Inc., 2018; Twitter Inc., 2018; Alphabet Inc., 2017).

As new publishing platforms have emerged, advertisers have remained central to media business models, acquiring new abilities to target viewers (Turow, 2011) and interact directly with consumers (Brodmerkal \& Carah, 2016). Social media platforms' advertising business started by serving banner ads to students and now cater to a complex global ecology of developers, brand pages, marketing partners, and ad publishers (Nieborg, 2017). Advertisers on social media platforms expect not only circulation, but also the ability to target specific 
categories of users, to have advertising content integrated into the look and function of the social media site, and to keep advertising separate from content that might be objectionable to their target audience-an ideal called "brand safety" (Trapp, 2016; Facebook, Google, and Twitter Executives on Russia Election Interference, 2017b, 1:40:36; Teich, 2017). Advertisers seek deeper relationships, including feelings and values, between consumers and brands (Banet-Weiser, 2012). Social media companies have made themselves central to meeting these preferences, and digital advertising is now a multimillion-dollar industry, with Facebook and Google earning more than half of that revenue (Ha, 2017; Reuters, 2017; Helmond, Nieborg, \& van der Vlist, 2017). Scholarship on social media platforms has already traced some of the ways in which accountability to advertisers has motivated significant changes to platform infrastructure, algorithms, and content policies (Gehl, 2014; Van Dijck, 2013; Helmond, 2015) and created a business model that permeates borders, incentivises the sharing of personal data, and wields affective forces to keep users connected (Karppi, 2018). While there have long been fears that advertiser agendas affect the production of media content, studies have tended to focus on advertisers securing positive reviews of their own content (Rinallo, Basuroy, Wu, \& Jeon, 2013) or on deceptive practices and native advertising (Carlson, 2015). The social media model has dispensed with conventions of "church-and-state" division between editorial and business concerns, making a virtue of its ability to integrate advertising content in ways tailored to achieve business goals (Couldry \& Turow, 2014).

Where newspaper advertisers were primarily national in their operations, advertising partners for the social media platforms are global and their audience, like that of the social media companies themselves, is often borderless. Social media companies face a fragmented policy environment and comparatively coherent economic incentives. Where Innis argued that the commercialism of media was part of US media imperialism, we can use the framework of the media megamachine identified above to trace the chains of command in new circumstances and to locate the "centrally directed" elements of the machine's programming (Mumford, 1966, p. 6). The social media megamachine is characterised by a policy environment strongly oriented toward self-regulation, where the ability to regulate exists but is often not exercised. Meanwhile, commercial incentives have become more granular and targeted towards outcomes at the level of content, affect, and quality of interaction with consumers, rather than only circulation. The next section examines the senate hearings with representatives of three major social media companies to better understand how pressure was applied to social media company representatives in a national context before comparing that process to interactions between advertisers and social media over content concerns. Doing so provides an illustrative comparison of how social media companies are governed in different institutional contexts.

\section{THE SENATE HEARINGS AND CONTROL OF SOCIAL MEDIA CONTENT}

The US senate hearings with representatives of social media companies over Russian activities during the 2016 presidential election were held 31 October and 1 November 2017 before the judiciary Subcommittee on Crime and Terrorism and the house and senate Committees on Intelligence. In his opening remarks, the republican chair of the judiciary subcommittee called social media platforms "portals" into US society and everyday life. The actions of the Internet Research Agency (IRA), located in St. Petersburg-the group that created group pages, advertisements, and events in the guise of American social and political groups-were central to the hearings and made a prime example of the failings of content regulation. Other examples, 
including the spread of false news stories on social media, extreme content, and political content posted outside of an election cycle, were also significant parts of the inquiry (Facebook, Google, and Twitter Executives on Russia Election Interference, 2017a, 1:24:10). False or sensationalised news have a long history in media and even the "filter bubble" is preceded by media that mirrors the preferences of its audience (Bennet and Iyengar, 2008). The ease with which such content is created and disseminated on social media has added urgency to questions about how to control that content. The hearings took place over a year after the initial problematic behaviour was identified. During that year, social media platforms resisted the idea that the problems were worth examining, repeatedly claiming that deception and misinformation on online platforms was minimal and of little significance to elections (Hudgins \& Newcomb, 2017).

During the hearings, the distance between the priorities of legislators and social media representatives was evident. Senate interlocutors repeatedly used the language and perspective of the national interest, including an interrogation centered on which nations social media companies consider a threat (Facebook, Google and Twitter Executives on Russian Disinformation, 2017). On the other side, the social media representatives argued that their tools are agnostic and "the internet is borderless", (34:05) meaning national sovereignties and enmities mean much less on social media platforms. These are opposing views, and not necessarily reconcilable, though many members, such as democrat Adam Schiff, sought reassurances that social media companies consider their corporate responsibility to include the protection of democratic communication within the US (Facebook, Google, and Twitter Executives on Russia Election Interference, 2017a). The representatives of the social media companies were careful to separate themselves from public service obligations. However, the license enjoyed by those companies is not guaranteed and the tech companies were careful to acknowledge moral and societal stakes and responsibilities. The rhetorical dance of nonobligation and self-regulation has historically allowed tech companies to align the companies with national interests or legislation in various national contexts in a largely self-regulated manner (Klonick, 2017).

The newspaper industry of Innis' analysis also had arms-length distance from the instruments of national governance, but, being located in the US and aligned with US interests through their readership, they had a more straightforward relationship with national politics. In the 2016 US election, much of the confusion and concern about the role of technology companies stemmed from the normalisation of social media content not made by or for US citizens. There was no reason, from the perspective of the tech companies to flag advertisements paid for in roubles because there are Russian companies online that might want to pay for advertisements for legitimate purposes. Twitter, in particular, argued that they were within their rights to partner with foreign media companies (Facebook, Google, and Twitter Executives on Russia Election Interference, 2017a). Both companies and senators admitted to having overlooked ordinary promotional tools and advertising for the dissemination of political content while focusing on cyber espionage efforts (Facebook, Google, and Twitter Executives on Russia Election Interference, $2017 \mathrm{~b}, 2: 23: 36)$. In the face of US scrutiny, the companies had two strategic options: either argue that the US government has no authority over them or demonstrate enough responsiveness and control over platform content to forestall government concerns, maintaining their social license as trustworthy partners. That was the strategy employed during the hearings. Representatives emphasised the proactive measures they had taken and their records of cooperation with national governments.

The central mechanism of dissemination of Russian content during the US presidential election was promotional tools. The IRA's actions in most respects resemble a public relations campaign. 
It used tools, including Facebook's Custom Audience Tool, A/B testing for advertisements, and geographic targeting, to reach a desired audience (Facebook, Google and Twitter Executives on Russian Disinformation, 2017). They also rolled out paid promotional campaigns, along with group pages that created content which could then be "boosted" to reach more people. It is a strategy that can be used by other groups-friendly or unfriendly, state or business-because it was designed to fit a range of globalised business needs and is resistant to governance outside of the social media companies themselves (Facebook, Google and Twitter Executives on Russian Disinformation, 2017). The use of mundane tools of business promotion to do the work of infiltrating US media lead many senators to question the legal disparity between media companies and social media companies. Offline, to comply with election spending limits, the purchaser and the purpose of any advertisement must be clearly identifiable. Online, the speed and volume of interactions, along with the comparatively light regulation enjoyed by the companies, have made it difficult to track the content of advertisements and consistently enforce standards (Facebook, Google and Twitter Executives on Russian Disinformation, 2017, 1:08:09). When flagging content for violations of terms of service, social media companies have until recently focused on the authenticity of accounts or behaviour rather than content. However, much of the behaviour that necessitated the inquiry was virtually indistinguishable from ordinary accounts until the connection between its origin and the content was made (Facebook, Google and Twitter Executives on Russian Disinformation, 2017, 2:12). Many companies that might not be appropriate advertisers during election cycles are legitimate users, by the standards of the platforms' terms of service, the rest of the time. The kinds of distinctions being made between acceptable and unacceptable content typically require human readers. During the hearings, social media companies, particularly Facebook, announced increases to their human moderation staff by, in some cases, tens of thousands. Google has made similar announcements in response to advertiser concerns over children's content on YouTube (Schindler, 2017).

The social media companies emphasised other existing initiatives that, they argued, demonstrated their proactive engagement with the problems identified after the 2016 election. Facebook has created Transparency Centres that allow users to check all the advertising campaigns a page is running on the platform, piloted election integrity initiatives in Canada (Valentino-Devries, 2018), and applied machine learning to control content around the 2017 German federal election (Lapowsky, 2017). These efforts have focused on user-facing transparency along with prompt identification and removal of offensive, dangerous, or inappropriate content, aided by machine learning. Overall, the hearings were marked by social media companies' insistence that the problems identified by the political representatives were already under control and that platform self-regulation should continue to be the norm. They did not suggest that institutional relationships between social media companies and policy regimes were under-developed. To prove their point, they indicated existing initiatives, particularly those focused on transparency, content review, and the proactive removal of offensive content. While they were presented to lawmakers as proactive measures that indicate the integrity of platform policies, these announcements closely resembled initiatives put in place earlier in 2017, in response to a different controversy on the platform.

\section{IAB, CONTENT SCANDALS, AND BRAND SAFETY}

In the spring of 2017, social media companies faced widespread outrage from advertisers whose ads had appeared next to objectionable content. Dozens of companies, including major global advertisers such as AT\&T, boycotted advertising on YouTube and elsewhere and demanded 
guarantees that the platforms were brand safe (Davies, 2017). To retain their advertising clients, the platforms were quick to create tools that allow marketing partners to review the placement of their ads and the content that they accompanied (Perez, 2017). The tools provided to advertisers-including machine learning to remove content, transparency centres, and human reviewers-resemble many of the initiatives social media companies cited in the US hearings as evidence of their proactive engagement of political misinformation. This section draws on industry coverage, including updates from trade groups such as the Interactive Advertising Bureau (IAB), to compare the two cases in more detail, and argue that the recycling in public hearings of steps taken to address commercial concerns indicates that, in some contexts, commercial actors may be able to drive the terms of platform governance more directly than policy processes.

This study examined IAB coverage, beginning from 20 March 2017 to establish a timeline of discussion and action between social media firms and advertisers during the brand safety crisis. Several developments outlined in the IAB's coverage are of interest to this paper. The first is the quick reaction of the social media companies to threats of boycotts from some of their core stakeholders. Procter \& Gamble announced a boycott of social media in early March 2017, and by the 31st Google had acknowledged the issues and created more conservative default advertising settings, as well as three new categories for excluding content. Where advertisers used to be able to opt out of running ads next to "sensitive subjects" and "tragedy and conflicts" they could now avoid content that might be "sexually suggestive", "sensational and shocking", or that might contain "profanity and rough language" (Sloane, 2017; Schindler, 2017). In contrast, the senate hearings over Russian misinformation in US elections took place more than a year after the initial reporting of misinformation and nearly a year after then-president Obama announced sanctions and investigations into Russian interference in the election (Sanger, 2016). During that year, the affected social media platforms denied the influence of Russian activities on their services and downplayed the significance of political messaging on their platforms (Hudgins \& Newcomb, 2017).

In a blog post outlining their responses to the brand safety crisis, Google articulated a dual responsibility to creators (including those with controversial views) and to advertisers. The commitments made by the company-to tighten safeguards by restricting ads to creators in YouTube's partner programme as well as to re-examine what kind of content to allow on the platform-were heavily weighted towards making sure that any content that is monetised is uncontroversial. Controls for advertisers include defaulting ads to narrower, more heavily vetted content, new tools to allow management of which sites and what content can appear next to ads, more options to exclude higher risk content and a commitment to sink more resources into content review by hiring more content reviewers and creating new machine learning tools (Schindler, 2017). During the senate hearings, increasing human content moderation and addressing content through artificial intelligence and machine learning were prominent in social media platforms' claims to be proactively addressing government concerns about political misuse of promotional tools. In addition to changing the defaults for advertisements, social media platforms, including YouTube and Facebook, opened their platforms to auditing by third parties closely affiliated with the IAB, such as the Media Rating Council, and made changes to YouTube's Preferred Partner Program. The Preferred Partner Program was formerly defined purely by the level of engagement with its content. It has been adjusted to reflect for heavily vetted content, specifically meant to be brand safe (Bardin, 2017). In the senate hearings, the platforms argued that the priorities of national governments are met through coordination between the platforms and government agencies, particularly with law enforcement agencies, and civil society groups. During the brand safety crisis, advertising interests were able to 
address their concerns directly to social media companies and get nearly immediate results, including powerful tools that changed how content on the platform was monetised - most likely with knock-on effects for what content is recommended. In contrast, government concerns are subject to coordination between disparate agencies, globalised civil society groups (some of whom resent companies taking credit for their role in social media moderation; Russell, 2018), and the social media companies. Thinking in terms of the hierarchies and accounting procedures that define the operation of the megamachine, there is a direct chain of accounting between globalised advertising interests and tools made by social media companies, while national interests and policies are represented by a host of competing interests. The concerns of advertisers were not subject to dispute in the way that national concerns were. While the platforms did claim that ads next to objectionable content were minimal, they also made concrete changes quickly after concerns were raised.

The brand safety crisis on YouTube was dubbed the "adpocalypse" after many individuals saw revenues for their channels drop drastically (Burgess \& Green, 2018). The fallout from YouTube's efforts to address brand safety concerns landed particularly on educational and LGBTQ content-content more likely to be flagged as "sensational and shocking" or "sexually suggestive" and therefore not necessarily brand safe. The commitments made by YouTube were meant to reassure advertisers that they can resume advertising on social media platforms-which most have done, though there continue to be problems with advertisements appearing next to objectionable content. They have strong implications for what content is monetised online, what is not, and how that is decided. The hazards of managing content this way are well articulated by Burgess and Green (2018), who argue that the role of advertisers in changing which topics are monetised on YouTube "problematically conflates sociocultural and political issues with commercial ones" (p. 151). The authors question whether brand safety initiatives will support diversity and inclusion when, in addressing violent and conspiratorial content, the adpocalypse also worked against sexual and gender minorities. It also showed a limited capacity for addressing the difference between inappropriate content and educational content, except in the case of professional media producers like the BBC. While advertisers have always been relatively conservative and risk-averse, the granular controls provided to them by social media allow them to more directly shape relationships between ads and content, and therefore the broader environment of content delivery.

This ability to shape content does not free advertisers or social media platforms from political pressure and social norms. Sometimes the closeness between social media and advertisers makes them targets for civil society efforts. In 2013, the Association for Progressive Communications and partners, including the Everyday Sexism Project, began communicating with Facebook advertisers whose content appeared next to images and text of violence against women. Within weeks of the campaign going public, the platform had taken action to address content that it had formerly resisted moderating (Fascendini, 2013; Levine, 2013; Pavan, 2017). The success of that campaign raises questions. For whom does that kind of pressure work? Advertisers are willing to boycott platforms on their own behalf and some are willing to act on behalf of other groups, such as women - an important consumer category - concerned about offensive content. Do political issues that are less commercially sensitive-LGBTQ media, Burmese speakers-have to take the "slow lane" of civil society and legal action? As Mueller (2015) demonstrates, it is a limited victory to win the legal right for a marginal group to speak if a platform cannot or does not continue to host that speech. There is no reason to think that any speech that is legal must also be monetisable. But if what is monetisable becomes the frontline of platform content governance, it is important to understand how those decisions are made and what their effects are. 


\section{CONCLUSION}

During the senate hearings, more than one senator challenged the social media companies' representatives to articulate their relationship to the nation in which they are based. As US democrat senator Amy Klobuchar, author of a bill that would harmonise advertising standards between online and offline media companies, remarked, any small radio station in the US is required to review every ad that runs on their station (Facebook, Google and Twitter Executives on Russian Disinformation, 2017, 2:55:59). The senate hearings are one of many recent examples of nations attempting to establish a clearer relationship between national priorities and online content. In the case of Klobuchar's Honest Ads bill, establishing the relationship is a matter of extending previous standards for content to new media players, given that cultural infiltration by hostile powers is not "new or novel" (Facebook, Google, and Twitter Executives on Russia Election Interference, 2017a, 00:00:33). This paper used the theoretical concept of the megamachine, with Innis' analysis of the newspaper industry as a template, to examine contemporary attempts to influence social media operations, following the chains of accounting and command between those directing the machine and those being directed by it. Both the newspaper industry and social media companies have a core product that acts as a "vendible commodity", attracting audiences who, in turn, attract advertisers. However, where Innis connected the business model of the print industry with US cultural imperialism, social media platforms' operations and major advertising clients are transnational and bridge many policy environments, complicating lines of accountability between the platforms and national governments. At the same time, advertiser's comparatively unified desire for targeted, brand safe content institutionalises closer relationships between advertising goals and the content moderation and monetisation policies of social media companies. Innis' analysis embedded media in the political economy of trade relationships and cultural products exchanged between the US and Canada, but examining his work as a megamachine allows insights into the administration of media content governance, which appears to have shifted towards transnational institutions as social media communications technologies cover more of the globe. With the emergence of social media, there is a renewed interest in content governance by both nations and advertisers. However, the advertisers have a head start in centralising their interests and building the infrastructure to see their vision of content governance respected, positioning them to be effective frontline governors of social media content.

Comparing the senate hearings with the brand safety controversy reveals correlating crises over content distribution online, stemming from inconsistently monitored placement of promoted materials. While this limited analysis is unable to reveal a core or causative relationship between the two, it does highlight similarities between actions presented to the US government in public hearings as proactive ways to address foreign interference and actions designed to assuage the concerns of advertisers over social media content. These similarities suggest a convergence between the actions needed to provide transparency in the advertising supply chain and the actions required to fulfill a public mandate for trustworthiness. Certainly, this comparison indicates that the architecture of social media companies is much more developed for meeting the concerns of advertisers than it is for regulators or public interest concerns. Advertising interests can demand concrete changes to social media platforms and see swift action to meet those demands, while even very powerful national governments may take the slow route of applying public pressure.

In her article on social media platforms as "the new governors", Klonick (2017) argues that the 
loss of equal access and participation and the lack of direct platform accountability are major causes for concern, even as social media platform policies largely follow the outlines of US speech laws. This paper has used the scholarship on the megamachine to think through patterns of accountability between media systems and their stakeholders. It has argued that commercial actors are able to exert considerable pressure on social media content moderation, acting sometimes ahead of government policy processes, and that the criteria for that governance is not principles of speech and representation, but the fuzzier criteria of brand values and brand safety. Rather than direct accountability to users or policy, social media companies are accountable to a range of stakeholders, and advertisers are often at the front of the line. It is possible that the interests of advertiser can serve to curb dangerous or extreme speech on social media platforms. Cunningham and Craig (2019), for instance, suggest advertisers may encourage better democratic norms in online communication "because most brands and advertisers will not tolerate association with such affronts to civility and democracy" (p. 8). It seems unlikely that the conservative nature of advertisers and brands is a substitute for governance of online spaces by regulators outside of the private sector, however-particularly as advertisers have limited investment in small countries, minority populations, and political communication. While the social media megamachine appears well designed to administer the interests of advertisers in content delivery, it is less efficient in facilitating the governance in other contexts-taking considerably longer to acknowledge and respond to democratic concerns over content.

Globally, there have been recent attempts to define the power of social media companies and to strengthen their accountability to national media policy regimes. Indicative of this tendency is the General Data Protection Regulation (GDPR), which came into force in the May of 2018, and is to date the most far-reaching move to directly regulate the actions of social media companies. However, representatives of the EU parliament indicated in a May 2018 hearing with Mark Zuckerberg that it is unlikely that the GDPR will change the business model of Facebook and other social media companies (EURACTIV, 2018). Advertisers have quickly adapted to the changes, shifting their spending to publishers with accurate first-party data (from memberships and mailing lists, for instance) and those with established reporting systems (Seb, 2018; Holton, 2018). While requirements for individual consent are stricter, the desire for large networks of circulation and brand-safe content may serve to entrench the power of established players who have the resources to ensure compliance and the long-term users who must agree to the terms to continue to use the service. Advertisers will spend money only in supply chains that are verified-that have audiences the advertisers know they can target both safely and legally (Holton, 2018). As such, the influence of advertiser preferences on their publishing partners will continue to strongly affect how content is moderated and monetised, even under this stricter regulatory burden. Recently, Facebook founder Mark Zuckerberg has argued for a more direct, globally standardised watchdog of public interests in the governance of content (Zuckerberg, 2019). Such a body might correct for the diffuse nature of national policy-making in comparison to the coherent agenda of advertising interests. Gillespie (2018) called Facebook "two intertwined networks, content and advertising, both open to all" (p. 203). Perhaps social media governance needs to acknowledge a similar division in its stakeholders and match the influence of the advertising industry with a transnational institution for political governance that addresses the democratic interest in social media content. 


\section{REFERENCES}

Alphabet, Inc. (2017). Annual Report 2016. Retrieved from https://www.sec.gov/Archives/edgar/data/1652044/o00165204417000008/goog10-kq42016. htm

Ardia, D. S. (2009). Free speech savior or shield for scoundrels: An empirical study of intermediary immunity under Section 230 of the Communications Decency Act. Loyola of Los Angeles Law Review, 43, 373-506. Available at https://scholarship.law.unc.edu/faculty_publications/37/

Bakshy, E., Messing, S., \& Adamic, L. A. (2015). Exposure to ideologically diverse news and opinion on Facebook. Science, 348(6239), 1130-1132. doi:10.1126/science.aaa1160

Banet-Weiser, S. (2012). AuthenticTM: The politics of ambivalence in a brand culture. New York: NYU Press.

Bardin, A. (2017, March 20). Strengthening YouTube for advertisers and creators. YouTube Creator Blog. Retrieved from https://youtube-

creators.googleblog.com/2017/o3/strengthening-youtube-for-advertisers.html

Bennett, W. L., \& Iyengar, S. (2008). A new era of minimal effects? The changing foundations of political communication. Journal of communication, 58(4), 707-731. doi:10.1111/j.1460-

2466.2008.00410.x

Berland, J. (1997). Space at the margins: Colonial spatiality and critical theory after Innis. TOPIA: Canadian Journal of Cultural Studies, 1(1). doi:10.3138/topia.1.55

Brodmerkel, S., \& Carah, N. (2016). Brand machines, sensory media and calculative culture. London: Palgrave Macmillan. doi:10.1057/978-1-137-49656-o

Burgess, J. (2015). From 'broadcast yourself' to 'follow your interests': Making over social media. International Journal of Cultural Studies, 18(3), 281-285.

doi:10.1177/1367877913513684

Burgess, J., \& Green, J. (2018). YouTube: Online Video and Participatory Culture. Cambridge: Polity Press.

Buxton, W. J. (1998). Harold Innis' excavation of modernity: the newspaper industry, communications, and the decline of public life. Canadian Journal of Communication, 23(3). doi:10.2223o/cjc.1998v23n3a1047

Carey, J. W. (1967). Harold Adams Innis and Marshall McLuhan. The Antioch Review, 27(1), 5-39. doi:10.2307/4610816

Couldry, N., \& Turow, J. (2014). Advertising, big data and the clearance of the public realm: marketers' new approaches to the content subsidy. International Journal of Communication, 8, 1710-1726. Retrieved from https://ijoc.org/index.php/ijoc/article/view/2166

Croteau, D., \& Hoynes, W. (2006). The Business of Media: Corporate Media and the Public Interest. Thousand Oaks, CA: Pine Forge Press.

Davies, J. (2017, April 4). The YouTube ad boycott concisely explained. Retrieved February 18, 
2019, from https://digiday.com/uk/youtube-ad-boycott-concisely-explained/

EURACTIV. (2018). Mark Zuckerberg's full meeting with EU Parliament leaders. Retrieved from https://www.youtube.com/watch?v=oozdBUOrhG8

Facebook Inc. (2018). Facebook Annual Report 2017. Retrieved from https://s21.q4cdn.com/399680738/files/doc_financials/annual_reports/FB_AR_2017_FINAL .pdf

Facebook, Google and Twitter Executives on Russian Disinformation: Hearing before the Senate Judiciary Subcommittee on Crime and Terrorism, Senate, $114^{\text {th }}$ Cong. (2017). Retrieved from https://www.c-span.org/video/?436454-1/facebook-google-twitter-executives-testifyrussia-election-ads

Facebook, Google, and Twitter Executives on Russia Election Interference: Hearing before the House Select Intelligence Committee, House, $114^{\text {th }}$ Cong. (2017a). Retrieved from https://www.c-span.org/video/?436362-1/facebook-google-twitter-executivestestify-russias-influence-2016-election

Facebook, Google, and Twitter Executives on Russia Election Interference: Hearing before the Senate Select Intelligence Committee, Senate, $114^{\text {th }}$ Cong. (2017b). Retrieved from https://www.c-span.org/video/?436360-1/facebook-google-twitter-executivestestify-russias-influence-2016-election

Fascendini, F. (2013, May 24). How funny is this, Facebook? Retrieved February 26, 2019, from Association for Progressive Communications Website https://www.apc.org/en/news/howfunny-facebook

Gallagher, R. (2018, August 1). Google Plans to Launch Censored Search Engine in China, Leaked Documents Reveal. The Intercept. Retrieved August 14, 2018, from https://theintercept.com/2018/o8/o1/google-china-search-engine-censorship/

Gehl, R. W. (2014). Reverse engineering social media: Software, culture, and political economy in new media capitalism. Philadelphia: Temple University Press.

Gillespie, T. (2018). Custodians of the Internet: Platforms, Content Moderation, and the Hidden Decisions That Shape Social Media. New Haven, NY: Yale University Press.

Gorwa, R. (2019). What is platform governance? Information, Communication \& Society, 22(6), 854-871. doi:10.1080/1369118X.2019.1573914

Ha, A. (2017, December 21). Digital ad spend grew 23 percent in the first six months of 2017 , according to IAB. Techcrunch. Retrieved from https://techcrunch.com/2017/12/20/iab-adrevenue-report-2017/

Helmond, A. (2015). The platformization of the web: Making web data platform ready. Social Media + Society, 1(2). doi:10.1177/2056305115603080

Helmond, A., Nieborg, D. B., \& van der Vlist, F. N. (2017). The Political Economy of Social Data: A Historical Analysis of Platform-Industry Partnerships. Proceedings of the 8th International Conference on Social Media \& Society - \#SMSociety17, 1-5. doi:10.1145/3097286.3097324

Holton, K. (2018, August 23). Europe's new data law upends global online advertising. Reuters. 
Retrieved from https://ca.reuters.com/article/businessNews/idCAKCN1L8oHW-OCABS

Hudgins, J., \& Newcomb, A. (2017, November 1). Google, Facebook, Twitter and Russia: A timeline on the '16 election. NBC News. Retrieved February 18, 2019, from

https://www.nbcnews.com/news/us-news/google-facebook-twitterrussia-timeline-16-election-n816036

Innis, H. A. (2007). Empire and communications. Lanham, MD: Rowman \& Littlefield.

Innis, H. A. (2008). The bias of communication (2nd ed.). Toronto: University of Toronto Press.

Isaac, M. (2016, November 22). Facebook said to create censorship tool to get back into China. The New York Times. Retrieved from

https://www.nytimes.com/2016/11/22/technology/facebook-censorship-tool-china.html

Karppi, T. (2018). Disconnect: Facebook's affective bonds. Minneapolis: University of Minnesota Press.

Klonick, K. (2017). The new governors: The people, rules, and processes governing online speech. Harvard Law Review, 131, 1598-1670.

Lapowsky, I. (2017, September 27). Facebook's crackdown ahead of German election shows it's learning. Wired. Retrieved from https://www.wired.com/story/facebooks-crackdown-aheadof-german-election-shows-its-learning/

Latour, B. (1999). Pandora's hope: Essays on the reality of science studies. Cambridge, MA: Harvard University press.

Levine, M. (2013, May 28). Controversial, harmful and hateful speech on Facebook. Retrieved February 26, 2019, from https://www.facebook.com/notes/facebook-safety/controversialharmful-and-hateful-speech-on-facebook/574430655911054

Medeiros, B. (2017). Platform (non-)intervention and the "marketplace" paradigm for speech regulation. Social Media + Society, 3(1), doi:10.1177/2056305117691997

Molotch, H. (1976). The city as a growth machine: Toward a political economy of place. American journal of sociology, 82(2), 309-332. doi:10.1086/226311

Mueller, M. L. (2015). Hyper-transparency and social control: Social media as magnets for regulation. Telecommunications Policy, 39(9), 804-810. doi:10.1016/j.telpol.2015.05.001

Mumford, L. (1966). The first megamachine. Diogenes, 14(55), 1-15.

doi:10.1177/039219216601405501

Nieborg, D. (2017, November 10). Facebook messenger and the political economy of platforms. Presentation given as part of the Marketing Research Seminar Series presented by the Schulich School of Business at York University.

Nipps, Karen. (2014). Cum privilegio: Licensing of the press act of 1662. The Library Quarterly: Information, Community, Policy, 84(4), 494-50o. doi:10.1086/677787

Pavan, E. (2017). Internet intermediaries and online gender-based violence. In M. Segrave \& L. Vitis (Eds.), Gender, Technology and Violence (pp. 62-79). Taylor \& Francis. 
doi:10.4324/9781315441160-5

Perez, S. (2017, Dec. 5). Youtube promises to increase content moderation and other enforcement staff to 10k in 2018. Techcrunch. Retrieved from https://techcrunch.com/2017/12/05/youtube-promises-toincrease-content-moderation-staff-to-over-1ok-in-2018/

Reuters. (2017, July 28). Why Google and Facebook prove that online advertising is a duopoly. Fortune. Retrieved from http://fortune.com/2017/o7/28/google-facebook-digital-advertising/

Rinallo, D., Basuroy, S., Wu, R., \& Jeon, H. J. (2013). The media and their advertisers: Exploring ethical dilemmas in product coverage decisions. Journal of Business Ethics, 114(3), 425-441. doi: 10.1007/s10551-012-1353-z

Russel, J. (2018, April 6). Myanmar group blasts Zuckerberg's claim on Facebook hate speech prevention. Techcrunch. Retrieved February 26, 2019, from http://social.techcrunch.com/2018/04/o6/myanmar-group-blasts-zuckerbergs-claim-on-faceb ook-hate-speech-prevention/

Schindler, P. (2017, March 20). Expanded safeguards for advertisers. Retrieved from https://blog.google/topics/ads/expanded-safeguards-for-advertisers/

Seb, J. (2018, June 25). A month after GDPR takes effect, programmatic ad spend has started to recover. Digiday. Retrieved August 18, 2018, from https://digiday.com/marketing/monthgdpr-takes-effect-programmatic-ad-spend-started-recover/

Shtern, J. (2009). Global internet governance and the public interest in communication (Unpublished doctoral dissertation). Université de Montréal, Montréal.

Sloane, G. (2017, Mar. 17). As Youtube tinkers with ad formula, its stars see their videos lose money. Adage. Retrieved from

http://adage.com/article/digital/youtube-feels-ad-squeeze-creators/308489/

Smith, G. (2017, January 25). Newspapers scale back Facebook and Snapchat content as meagre advertising returns disappoint. The Independent. Retrieved from

http://www.independent.co.uk/news/business/news/newspapers-facebook-snpachat-advertsmeagre-returns-news-media-outlets-social-media-money-earnings-a7545331.html

Teich, D. (2017, June 14). How Youtube handled its brand safety crisis. Digiday. Retrieved from https://digiday.com/marketing/youtube-handled-brand-safety-crisis/

Trapp, F. (2016, April 15). Algorithm and advertising: The real impact of Instagram's changes. Adweek. Retrieved from

http://www.adweek.com/digital/francis-trapp-guest-post-instagram-algorithm/

Turow, J. (2012). The daily you: How the new advertising industry is defining your identity and your worth. New Haven, CT: Yale University Press.

Twitter, Inc. (2018). Annual report 2018. Retrieved from http://files.shareholder.com/downloads/AMDA-2F526X/6366391326xox976375/oD3956oE-C 8B5-4BAo-83C4-C9B5C88D4737/TWTR_2018_AR.pdf

Valentino-Devries, J. (Jan. 31, 2018). Facebook's experiment in ad transparency is like playing 
hide and seek. Propublica.org. Retrieved from https://www.propublica.org/article/facebookexperiment-ad-transparency-toronto-canada

van Dijck, J. (2013). The culture of connectivity: A critical history of social media. Oxford: Oxford University Press.

$\mathrm{Wu}, \mathrm{T}$. (2016). The attention merchants: The epic scramble to get inside our heads. New York: Knopf.

Yeung, K. (2017). 'Hypernudge': Big data as a mode of regulation by design. Information, Communication \& Society, 20(1), 118-136. doi:10.1080/1369118X.2016.1186713 